\title{
Determinants of health-related quality of life in elderly in Tehran,
} Iran

\author{
Maryam Tajvar ${ }^{\dagger 1,2}$, Mohammad Arab ${ }^{\dagger 2}$ and Ali Montazeri*3
}

Address: ${ }^{1}$ London School of Hygiene and Tropical Medicine, London, UK, ${ }^{2}$ Department of Health Management and Economics, Tehran University of Medical Sciences, Tehran, Iran and ${ }^{3}$ Iranian Institute for Health Sciences Research, Tehran, Iran

Email: Maryam Tajvar - Maryam.Tajvar@lshtm.ac.uk; Mohammad Arab - arabmoha@sina.tums.ac.ir; Ali Montazeri* - montazeri@acecr.ac.ir

* Corresponding author †Equal contributors

Published: 22 September 2008

BMC Public Health 2008, 8:323 doi:10.1 I86/147|-2458-8-323
Received: 7 May 2008

Accepted: 22 September 2008

This article is available from: http://www.biomedcentral.com/I47I-2458/8/323

(C) 2008 Tajvar et al; licensee BioMed Central Ltd.

This is an Open Access article distributed under the terms of the Creative Commons Attribution License (http://creativecommons.org/licenses/by/2.0), which permits unrestricted use, distribution, and reproduction in any medium, provided the original work is properly cited.

\begin{abstract}
Background: As Iran started to experience population ageing, it is important to consider and address the elderly people's needs and concerns, which might have direct impacts on their wellbeing and quality of life. There have been only a few researches into different aspects of life of the elderly population in Iran including their health-related quality of life. The purpose of this study was to measure health-related quality of life (HRQoL) of elderly Iranians and to identify its some determinant factors.
\end{abstract}

Methods: This was a cross-sectional survey of a random sample of community residents of Tehran aged 65 years old and over. HRQoL was measured using the Short From Health Survey (SF-36). The study participants were interviewed at their homes. Uni-variate analysis was performed for group comparison and logistic regression analysis conducted to predict quality of life determinants.

Results: In all, 400 elderly Iranian were interviewed. The majority of the participants were men (56.5\%) and almost half of the participants were illiterate $(n=199,49.8 \%)$. Eighty-five percent of the elderly were living with their family or relatives and about $70 \%$ were married. Only $12 \%$ of participants evaluated their economic status as being good and most of people had moderate or poor economic status. The mean scores for the SF-36 subscales ranged from 70.0 (SD $=25.9$ ) for physical functioning to $53.5(S D=29.1$ ) for bodily pain and in general, the respondents significantly showed better condition on mental component of the SF-36 than its physical component (mean scores 63.8 versus 55.0). Performing uni-variate analysis we found that women reported significantly poorer HRQoL. Multiple logistic regression analysis showed that for the physical component summary score of the SF-36, age, gender, education and economic status were significant determinants of poorer physical health-related quality of life; while for the mental component summary score only gender and economic status were significant determinants of poorer mental health-related quality of life. The analysis suggested that the elderly people's economic status was the most significant predictor of their HRQoL.

Conclusion: The study findings, although with a small number of participants, indicate that elderly people living in Tehran, Iran suffer from relatively poor HRQoL; particularly elderly women and those with lower education. Indeed to improve quality of life among elderly Iranians much more attention should be paid to all aspects of their life including their health, and economic status. 


\section{Background}

We live in a 'population ageing' era. Population ageing has progressed furthest in developed countries but developing countries have also begun to experience considerable increases in their proportion of elderly people [1,2]. Iran has started to come across with the population ageing phenomenon too. Although, Iran still has a relatively young population, the proportion of elderly is projected to double in less than 20 years [3]. The United Nations statistical projections demonstrate rapid growth of elderly population in Iran. While the proportion of people with 60 years old age and above in Iran was 5.4 percent in 1975 it will increase to 10.5 percent in 2025 and 21.7 percent in 2050 [4]. In fact the total size of population of Iran will fail to double in the next fifty years, but the number of elderly aged 65 years and over will experience about six-fold increase [5]. Thus, it is no longer possible to ignore the commencing ageing phenomenon in Iran and therefore, it is vital to anticipate requirements of this age group in Iran to plan appropriate policies to address their growing needs and to support their quality of life.

In Iran the elderly are treated very respectfully and they are privileged by a high position among the family members and are supported by their family for all their needs. The Islam also supported this belief where $95 \%$ of the general populations and 99.2\% of the elderly are Muslim [6,7]. There are several verses in the Quran stating that Muslims should appreciate and regard the elderly as valuable and precious members of community (e.g. Verse 23 of Asra Surah, Quran). There are also many poems and expression in Persian literature regarding the respected position of elderly in families and in the community as the builders of our past and the repository of life experiences. In Iran, while considerable decline appears in the health of the elderly through getting older, their ability to obtain their health needs seems even getting worse than before. It happens because most of people loose their income source in ageing period and become economically dependent to others. On the other hand, medical expenses and prices increase every year in Iran and this issue deteriorates the ability of elderly to pay for their medical needs particularly for those lacking any medical insurances [8]. According to a survey, 25 to $30 \%$ of the elderly in Iran did not benefit from any medical insurance services [7]. Therefore, thousands of old men and women are likely to face further hazards for their health in Iran. However, only a few studies have been conducted in Iran on different aspects of life of the elderly including their health-related quality of life (HRQoL).

HRQoL is a subdivision of QoL, and most commonly refers to people's experience of their global health. It may also refer to health-related subjective well-being, functional status, or self-perceived health $[9,10]$. A representa- tive definition of HRQoL is "a multi-dimensional concept that encompasses the physical, emotional, and social components associated with an illness or treatment" [11]. However, health related quality of life for the elderly people might be described in terms of functional status, independence and ability to engage in life activities [12]. An important aim of research into HRQoL in this age group is to enable older people to maintain their mobility, independence, their active contribution to society, and to respond effectively to the challenges of older age and in general bring an active aging for them [13]. It is argued that the increasing international interest in research into HRQoL is partly due to global population ageing, as a longer life is often associated with a higher proportion of chronic diseases and functional impairments [7]. The elderly with chronic disorders often experience a burden of diseases that adversely influence their HRQoL [5]. Therefore, investigating HRQOL of the elderly is especially important because health issues limit their independence and ability to engage in life activities.

Health-related quality of life and its determinants in older people is well documented in developed world. For instance, a study by Gallicchio et al. [14] showed that poor social networks are associated with worse physical health and mental well-being. Other factors such as living in poor housing, inadequate finances and inadequate social relationships were also important factors leading to deterioration in QoL [13]. Farquhar [15] reported that older people identified family relationship, health, standard of living, activities and other social contacts important to bring quality to their life. Bowling [13] also revealed that good health, good social relationship, having social activities, good financial circumstances and being independent significantly would increase QoL in elderly populations. However, health-related quality of life and its determinants in elderly are not researched adequately in Iran. Thus, this study sought to assess HRQoL in a sample of elderly of Tehran in order to identify some of its contributing factors. Understanding the factors contributing to HRQoL is critical for developing the most appropriate interventions for improving or preserving QoL. In this study we examined the association between several important characteristics of elderly people in Tehran including sex, age, education, living status, marital status and economic status with HRQoL. We were interested to understand whether these variables are the significant predictors for HRQoL in the elderly people or not. We hoped that the result of this research could effectively contribute to the challenges of people with older age in Iran.

\section{Methods}

\section{Study design and data collection}

This was a cross-sectional survey of a random sample of elderly Iranians selected from the general population in 
Tehran. Tehran has more than 7 million inhabitants and 22 districts and it is most densely populated region in Iran [16]. The sampling method was based on a multi-stage stratified sampling approach. Information on the total number of households and their addresses were available for all districts (provided by the municipality of Tehran). Proportionate allocation sampling was used to identify a sampling fraction for each of the districts. Then, random sampling was applied within each stratum to select the required households in the districts to ensure that every household within the districts has the same probability of being sampled. All participants were interviewed at their home. Those who were not available for interview at given time were asked for another appointment. Twelve interviewers were trained to collect the data.

\section{Measure of health-related quality of life}

We used the Iranian version of Short Form Health Survey (SF-36) questionnaire to collect data on HRQoL. The SF36 is a well-known generic HRQoL instrument that was developed initially in the United State of America. Its reliability and validity has been approved not only in multiple populations in several studies, but also for elderly people in some surveys [17]. The psychometric properties of the Iranian version of the SF-36 (interview administered) are well documented [18].

The SF-36 includes 8 subscales namely: Physical functioning (PF), Role physical (RP), Bodily pain (BP), General health (GH), Vitality (VT), Social functioning (SF), Role emotional (RE), and Mental health (MH). It also provides two summary scales, Physical Component Summary (PCS) and Mental Component Summary (MCS). Scores range from 0 to 100 for each subscale with higher scores indicating a better condition.

\section{Independent variables}

The other data collected were included sex, age, education, living status, marital and economic status. The living status of the elderly was represented by two main categories living alone or with others. Marital status was categorized into two main subgroups; married and non-married people. Education was categorized into three groups: illiterate, middle literacy, and university education. This was done due to the fact that illiteracy and university education have significant impact on the health status of elderly people in Iran, while people with an education level between the two mentioned levels are usually the same (although too broad). Thus, all people other than the two indicated groups were catagroized as "middle literacy" group as we believed that they may not have significant socioeconomic differences considering Iran's current condition. Finally, the economic status of people was indicated by asking each individual to respond to the question "In general, how would you describe your economic status at present"? There were three response categories: poor, intermediate, and good. It has been shown that this is generally a reliable method to collect such information as people are able to accurately rate their economic status with respect to the community condition and compare themselves with others [19].

\section{Data analysis}

The data were analyzed using both descriptive and analytical approaches. The normality of the data (the SF-36 scores) was examined. Although score distributions slightly were negatively skewed, all were found to be satisfactory (all skewness values less than one). To examine the association between the participants' characteristics and their HRQoL, uni-variate statistical tests including T-Tests and One-way analysis of variance (ANOVA) were performed. To indicate determinant factors of HRQoL multiple logistic regression analysis was applied. For the purpose of the logistic regression analysis Physical Component Summary (PCS) and Mental Component Summary (MCS) were used and relative to the mean scores the study sample were divided into two groups; those who scored equal or greater than mean (PCS: $n=206 ;$ MCS: $n$ $=227$ ) and those who scored below mean (PCS: $\mathrm{n}=194$; MCS: $\mathrm{n}=173$ ).

\section{Ethical considerations}

This study received approval from the ethics committee of Tehran University of Medical Sciences (TUMS). All participants gave their oral consents for interview. We kept the information of the participants confidential.

\section{Results}

In all, 400 elderly Iranians aged 65 years and over were interviewed. As shown in Table 1, 56.5\% of the participants were men. The mean age of participants was 72 years $(\mathrm{SD}=6.3)$. Only a few people, $4.5 \%$, had university education and approximately half were illiterate. Most were living with family or relatives $(85 \%)$ at the time of interview. $62.7 \%$ were married. Of total participants, $35.8 \%$ described their own economic status poor, $52.2 \%$ moderate and the remaining $12 \%$ good.

Table 2 presents HRQoL scores as measured by the SF-36. The mean (SD) of physical and mental summary scores were 55.01 (25.66) and 63.86 (23.86) respectively; indicating that the mental status of the participants was significantly better than their physical condition $(P<0.0001)$.

The association between the participant's socio-demographic characteristics and their HRQoL was also examined. Table 3 summarizes the results.

There were significant differences between men and women on all the SF-36 and the PCS and the MCS scores 
Table I: Frequency distribution of the participant's demographical characteristics $(n=400)$

\begin{tabular}{llll}
\hline & & Number & Percent (\%) \\
\hline Sex & & & \\
& Female & 174 & 43.5 \\
Age & Male & 226 & 56.5 \\
& & & \\
& $65-69$ & 153 & 38.3 \\
& $70-74$ & 126 & 31.5 \\
Living status & $75-79$ & 61 & 15.3 \\
& $80+$ & 60 & 15.0 \\
& & & \\
Education & Alone & 60 & 15.0 \\
& With others & 340 & 85.0 \\
& Illiterate & 199 & 49.8 \\
& Middle literacy & 183 & 45.8 \\
Marital Status & University education & 18 & 4.5 \\
& & & \\
& Married & 279 & 69.8 \\
Economic Status & Non-married & 121 & 30.2 \\
& Poor & 143 & 35.8 \\
& Intermediate & 209 & 52.2 \\
& Good & 48 & 12
\end{tabular}

indicating that older women reported significantly poorer HRQoL compared with men $(\mathrm{P}<0.0001)$. Scores were not significantly different among age groups but for the physical functioning and the role physical $(\mathrm{P}<0.0001)$. The results also demonstrated that there were statistically significant differences in HRQoL of the respondents in terms of their educational level $(\mathrm{P}<0.0001)$. Higher education was associated with better HRQoL in all aspects of the SF36 . The elderly living with others had a higher average in all HRQoL scales compared to people living alone $(\mathrm{P}<$ $0.0001)$. However, this difference was not statistically significant for vitality, role emotional and mental health subscales. The married elderly living with their spouse had higher HRQoL scores compared with those who were not

Table 2: Mean scores of HRQoL of elderly in Tehran as measured by the SF-36

\begin{tabular}{lcc}
\hline Scales & Means & SD \\
\hline Physical functioning (PF) & 54.96 & 30.65 \\
Role physical (RP) & 56.37 & 48.18 \\
Bodily pain (BP) & 53.59 & 29.10 \\
General health (GH) & 55.11 & 21.06 \\
Vitality (VT) & 55.87 & 24.08 \\
Social functioning (SF) & 70.93 & 25.93 \\
Role emotional (RE) & 65.50 & 45.68 \\
Mental health (MH) & 63.14 & 22.33 \\
Physical Component Summary (PCS) & 55.01 & 25.66 \\
Mental Component Summary (MCS) & 63.86 & 23.86
\end{tabular}

married $(P<0.000)$. Furthermore, the elderly enjoying by a high economic status in the community had higher HRQoL scores $(\mathrm{P}<0.0001)$.

To indicate determinant factors of HRQoL, multiple logistic regression analysis was performed. As indicated in Table 4, the results showed that for the PCS age, sex, education and economic status were significant determinants. The results showed no significant results for living condition and marital status either. However, for the MCS the results showed a relatively different perspective indicating that only sex and economic status were significant determinants. Age, marital status, education and living condition did not show significant results although the findings were in the expected direction.

The analysis suggested that the elderly people's economic status was the most significant predictor of a better or a poorer physical and mental health-related quality of life scores.

\section{Discussion}

In general, based on the findings of the present study we might conclude that HRQoL in participants, particularly physical health, was rather poor; although the study sample was small and the results could not be generalized to entire elderly population in Iran. To explain such findings one might argue that most elderly Iranian are poor and often their income does not adequately cover their living expenses and thus the elderly, particularly women, face multiple problems that influence the quality of their life $[20,21]$. The results of the first national survey in 1998 on health and ageing in Iran showed that the employment rate was $42-64 \%$ among elderly males while just $2.7-$ $9.3 \%$ of females were paid employees. Urban seniors paid more visits to physicians compared with rural seniors; 20 $25 \%$ experienced a trauma in a year that could lead to special therapeutic and medical measures, $25 \%$ of urban and $35 \%$ of rural elderly needed eyeglasses or lenses, and more than $50 \%$ of elderly people had a disability on moving and transfer, such as arthritis or osteoporosis [7]. In addition, one might attribute the findings to poor health care services for elderly people compared to the general population due to several factors including economic barriers [22].

We found that elderly people in this study had a better mental health condition compared to their own physical health. This might reflect the socio-cultural position that elderly people poses in Iran. The dominant Iranian culture places a high position for old people among the family members and relatives and embeds a good social relationship between young and old members. The high score for social functioning subscale may also support this explanation. 
Table 3: Association between the SF-36 scores and socio-demographical characteristics of the study sample

\begin{tabular}{|c|c|c|c|c|c|c|c|c|c|c|c|}
\hline \multirow[t]{2}{*}{ Scales } & \multicolumn{2}{|l|}{ Sex } & \multirow[t]{2}{*}{$P$ value } & \multicolumn{4}{|c|}{ Age Groups } & \multirow[t]{2}{*}{ P-value } & \multicolumn{2}{|c|}{ Marital Status } & \multirow[t]{2}{*}{ P-value } \\
\hline & $\begin{array}{l}\text { Male } \\
\text { mean } \\
(S D)\end{array}$ & $\begin{array}{l}\text { Female } \\
\text { mean }(S D)\end{array}$ & & $\begin{array}{c}65-69 \\
\text { mean }(S D)\end{array}$ & $\begin{array}{c}70-74 \\
\text { mean }(S D)\end{array}$ & $\begin{array}{l}75-79 \text { mean } \\
\text { (SD) }\end{array}$ & $\begin{array}{l}80+\text { mean } \\
\quad(S D)\end{array}$ & & $\begin{array}{c}\text { Married } \\
\text { mean (SD) }\end{array}$ & $\begin{array}{l}\text { Unmarried } \\
\text { mean (SD) }\end{array}$ & \\
\hline $\mathrm{PF}$ & $62(29)$ & $45.7(30.2)$ & 0.000 & $62.6(30.2)$ & $55.4(29.5)$ & $48.5(29.6)$ & $40.9(29.3)$ & 0.001 & $59.1(29.5)$ & $45.2(31.1)$ & 0.000 \\
\hline $\mathrm{RP}$ & $62.3(47)$ & $48.5(48.5)$ & 0.004 & $69.2(44.8)$ & $54.9(48.9)$ & $38.9(47.5)$ & $44.1(47.2)$ & 0.000 & $61.4(46.9)$ & $44.6(49)$ & 0.001 \\
\hline $\mathrm{BP}$ & $62.3(27.7)$ & $42.1(26.7)$ & 0.000 & $57(28.9)$ & $52.3(27.5)$ & $51.5(32.3)$ & $49.5(28.9)$ & 0.105 & $58.1(28.4)$ & $43(27.8)$ & 0.000 \\
\hline $\mathrm{GH}$ & $59.9(19.4)$ & $48.7(21.4)$ & 0.000 & $57.1(19.9)$ & $53.8(21.8)$ & $53.7(22)$ & $54(21.1)$ & 0.409 & $57.2(20.5)$ & $50.1(21.3)$ & 0.002 \\
\hline VT & $62.2(21.4)$ & $47.5(24.8)$ & 0.000 & $58.8(24.1)$ & $55.1(23.5)$ & $52.4(22.6)$ & $53.2(26)$ & 0.394 & $58.7(22.8)$ & $49.7(25.7)$ & 0.000 \\
\hline SF & $\begin{array}{l}74.8 \\
(23.9)\end{array}$ & $65.8(27.5)$ & 0.001 & $72.4(25)$ & $71.9(25.5)$ & $67.6(27.6)$ & $68.3(27.3)$ & 0.264 & $73.3(24.6)$ & $65.2(28)$ & 0.004 \\
\hline RE & $72.2(42.8)$ & $56.7(47.8)$ & 0.001 & $68.8(45.3)$ & $63.4(46.2)$ & $61.7(46.6)$ & $65(44.8)$ & 0.154 & $76(45)$ & $61.9(47.2)$ & 0.311 \\
\hline $\mathrm{MH}$ & $67(20.7)$ & $58(23.3)$ & 0.000 & $64.8(21.8)$ & 62.7(22.9) & $60.6(23.2)$ & $62.3(21.5)$ & 0.475 & $65.5(21.4)$ & $57.6(23.3)$ & 0.001 \\
\hline PCS & $61(24.1)$ & $46.3(25)$ & 0.000 & $61.5(24.7)$ & $54.1(25.1)$ & $48.1(26.6)$ & $47.1(24.4)$ & 0.058 & $59(24.8)$ & $45.7(25.2)$ & 0.000 \\
\hline MCS & $69.1(22)$ & $57(24.4)$ & 0.000 & $66.2(23.2)$ & $63.3(24.6)$ & $60.6(24.7)$ & $62.2(23)$ & 0.655 & $66.1(23)$ & $58.5(25)$ & 0.003 \\
\hline \multirow[t]{2}{*}{ Scales } & \multicolumn{2}{|l|}{ Living status } & $P$ value & \multicolumn{3}{|c|}{ Education } & P-value & \multicolumn{3}{|c|}{ Economic Status } & P-value \\
\hline & $\begin{array}{l}\text { Alone } \\
\text { mean } \\
(\mathrm{SD})\end{array}$ & $\begin{array}{l}\text { With } \\
\text { others } \\
\text { mean (SD) }\end{array}$ & & $\begin{array}{c}\text { Illiterate } \\
\text { mean (SD) }\end{array}$ & $\begin{array}{c}\text { Middle } \\
\text { literacy } \\
\text { mean (SD) }\end{array}$ & $\begin{array}{l}\text { University } \\
\text { education } \\
\text { mean(SD) }\end{array}$ & & $\begin{array}{l}\text { Poor } \\
\text { mean } \\
(\mathrm{SD})\end{array}$ & $\begin{array}{l}\text { Intermedia } \\
\text { te mean } \\
\text { (SD) }\end{array}$ & $\begin{array}{c}\text { Good } \\
\text { mean (SD) }\end{array}$ & \\
\hline PF & $43.4(33)$ & $57(29.8)$ & 0.001 & $46.5(29.3)$ & $63.1(29.6)$ & $64.4(30.6)$ & 0.000 & $45.1(3 \mid .7)$ & $58(27.9)$ & $72(28.8)$ & 0.000 \\
\hline $\mathrm{RP}$ & $42(49.4)$ & $58.8(47.5)$ & 0.013 & $47.1(48.7)$ & $65.9(46)$ & $61.1(46.3)$ & 0.001 & $39(47.2)$ & $63.1(46.7)$ & $79.1(4 I)$ & 0.000 \\
\hline $\mathrm{BP}$ & $43.6(28.5)$ & $55.3(28.8)$ & 0.004 & $45.7(27.4)$ & $60.6(28.8)$ & $68.3(26.2)$ & 0.000 & $46.7(28.1)$ & $56.4(28.8)$ & $62(29.9)$ & 0.000 \\
\hline $\mathrm{GH}$ & $48.4(20.8)$ & $56.3(20.9)$ & 0.007 & $50.1(21.1)$ & $60.1(19.7)$ & $59.7(21.1)$ & 0.000 & $47.5(19.8)$ & $58.5(20.7)$ & $63.4(19.2)$ & 0.000 \\
\hline VT & $50.8(24.9)$ & $56.7(23.8)$ & 0.079 & $49.3(22.1)$ & $62(24.3)$ & 65.2(23.4) & 0.000 & $47.8(23)$ & $58.5(23.2)$ & $69.2(22.2)$ & 0.000 \\
\hline SF & $61.6(28.6)$ & $72.5(25.1)$ & 0.003 & $66.7(25.1)$ & $75(26.2)$ & $75.6(25.1)$ & 0.005 & $62.1(26.9)$ & $74.9(24)$ & $79.9(23.5)$ & 0.000 \\
\hline RE & $61.1(47.9)$ & $66.2(45.2)$ & 0.420 & $56.9(47.5)$ & $73.2(42.7 I)$ & $81.4(36.55)$ & 0.001 & $50.9(48.4)$ & $72.1(42.7)$ & $80.5(39.4)$ & 0.000 \\
\hline $\mathrm{MH}$ & $58.9(20.9)$ & $63.8(22.5)$ & 0.114 & $57.4(22)$ & $68.9(20.9)$ & $66.8(24)$ & 0.000 & $55.6(20.8)$ & $66(28.8)$ & $74(21.5)$ & 0.000 \\
\hline PCS & $44.4(26.9)$ & $56.8(25)$ & 0.000 & $47.3(24.9)$ & $62.4(24.5)$ & $63.4(19.6)$ & 0.000 & $44.6(25.5)$ & $59(23.6)$ & $69.2(23)$ & 0.000 \\
\hline MCS & $58.1(24.9)$ & $64.8(23.5)$ & 0.044 & $57.6(22.8)$ & $69.8(23.5)$ & $72.3(20)$ & 0.000 & $54.1(23.5)$ & $67.9(22.2)$ & $75.9(21.4)$ & 0.000 \\
\hline
\end{tabular}

Examination of the associations between HRQoL subscales and socio-demographical factors demonstrated clear patterns. We observed that women had significantly poorer HRQoL in all scales compared with men. All available studies on HRQoL in Iran without exception obtained the same results that can be interpreted as significant gender inequalities in health in Iran $[18,22,23]$. In general Iranian women (particularly old women) have less access to information, education, and employment and in overall disadvantaged economic status and social position compared with men. This cause a weaker access to resources and decision-making positions which constrain women's ability to influence resource allocation, investment and expenditure decisions [24]. All the above matters definitely generate a worse health status and HRQoL for women. Similarly studies of HRQoL worldwide including Finland, Taiwan, Poland and Croatia, Japan and Korea have found that women were less advantaged group compared to male group [25-29]. Although women on average live longer than men, they report more illness than men [30]. Estimates of healthy life expectancy from 2002 showed that in almost all countries women have fewer healthy years of life than men [31]. The condi- tion for Iranian women is in average even worse than condition for women in rest of the world. The lower proportion of females than elderly males in Iran in comparison with other countries also reflects the disadvantaged life conditions for females. Improving women's health and their HRQoL demands a multi-sectional, multi-disciplinary, and culturally relevant approach to create a suitable environment for providing better living conditions for women.

We observed that age, not surprisingly, negatively affects the HRQoL mostly on physical health than mental health. It, however, have been discussed that if elderly have satisfactory living conditions, increasing age may not result in deterioration of their mental health $[32,33]$. Thus, the attempts should be made to delay or limit the impact of age on the body in order to give higher quality to the life of the aging population.

A strong association was observed between education and HRQoL. According to Lasheras [34] lower educational level is associated with unhappiness, poor social relationships, poor self-assessed health, and sensory problems 
Table 4: Determinants of poor physical and mental healthrelated quality of life in elderly participants

\begin{tabular}{|c|c|c|}
\hline & OR $(95 \% \mathrm{Cl})$ & $P$ \\
\hline \multicolumn{3}{|l|}{ Physical Component Summary (PCS) } \\
\hline \multicolumn{3}{|l|}{ Age } \\
\hline $65-69$ & I.0 (ref.) & \\
\hline 70-74 & I.48 $(0.88-2.48)$ & 0.13 \\
\hline $75-79$ & $2.36(1.21-4.59)$ & 0.01 \\
\hline $80 \geq$ & $2.62(1.33-5.14)$ & 0.005 \\
\hline \multicolumn{3}{|l|}{ Sex } \\
\hline Male & I.0 (ref.) & \\
\hline Female & $2.42(1.44-4.04)$ & 0.001 \\
\hline \multicolumn{3}{|l|}{ Marital status } \\
\hline Married & I.0 (ref.) & \\
\hline Never married/widowed/divorced & $1.31(0.70-2.43)$ & 0.39 \\
\hline \multicolumn{3}{|l|}{ Education } \\
\hline Literate & I.0 (ref.) & \\
\hline Illiterate & $\mathrm{I} .52(0.96-2.4 \mathrm{I})$ & 0.07 \\
\hline \multicolumn{3}{|l|}{ Economic status } \\
\hline Good & I.0 (ref.) & \\
\hline Intermediate & $1.76(0.85-3.64)$ & 0.12 \\
\hline Poor & $4.0(1.83-8.70)$ & $<0.0001$ \\
\hline \multicolumn{3}{|l|}{ Living condition } \\
\hline With family/relatives & I.0 (ref.) & \\
\hline Alone & $1.05(0.49-2.24)$ & 0.89 \\
\hline \multicolumn{3}{|l|}{ Mental Component Summary (MCS) } \\
\hline \multicolumn{3}{|l|}{ Age } \\
\hline $65-69$ & I.0 (ref.) & \\
\hline 70-74 & $1.25(0.75-2.10)$ & 0.38 \\
\hline 75-79 & $1.29(0.68-2.48)$ & 0.42 \\
\hline $80 \geq$ & $1.47(0.76-2.83)$ & 0.24 \\
\hline \multicolumn{3}{|l|}{ Sex } \\
\hline Male & I.0 (ref.) & \\
\hline Female & $2.48(1.50-4.12)$ & $<0.0001$ \\
\hline \multicolumn{3}{|l|}{ Marital status } \\
\hline Married & I.0 (ref.) & \\
\hline Never married/widowed/divorced & $0.99(0.54-1.83)$ & 0.99 \\
\hline \multicolumn{3}{|l|}{ Education } \\
\hline Literate & I.0 (ref.) & \\
\hline Illiterate & $1.20(0.75-1.89)$ & 0.43 \\
\hline \multicolumn{3}{|l|}{ Economic status } \\
\hline Good & I.0 (ref.) & \\
\hline Intermediate & $2.26(1.06-4.8 I)$ & 0.03 \\
\hline Poor & $4.85(2.18-10.8)$ & $<0.0001$ \\
\hline \multicolumn{3}{|l|}{ Living condition } \\
\hline With family/relatives & I.0 (ref.) & \\
\hline Alone & $\mathrm{I} .07(0.5 \mathrm{I}-2.2 \mathrm{I})$ & 0.85 \\
\hline
\end{tabular}

among the elderly. Education is an important indicator that may directly or indirectly influence HRQoL through its association with higher social class and economic status [35].

The present study also showed a better HRQoL for the elderly living with others compared to those living alone. Likewise, married people enjoyed by a higher HRQoL than widowed, single and divorced elderly. The study by Vahdainia et al. [23] showed that elderly living with their spouse in Tehran had better HRQoL in all 8 subscales of the Sf-36 compared with those who were widowed or divorced. Victor et al. [36], and Walker [37] argued that low amount of social participation and being alone is often associated with poor HRQoL in old ages. According to the study by Bowling et al. [38] poor psycho-social health and feelings of loneliness has been seen among those living alone due to lack of emotional support within the household, and an absence of practical support. However, others presented different perspective and argued that living alone is not necessarily the same as feeling loneliness and experience a poor QoL $[36,39]$. Some researchers believe that poor health is often a reason for moving to live with a relative. Therefore, the elderly who live with relatives may have poorer health than those living alone [13]. However, differences in the above perspectives reflect diversity in cultural and social conditions of communities.

In Iran, the cultural and religious background is not in favor of leaving elderly people alone and encourages younger people to take care of their elderly parents; while in developed societies often older people value their independence and may prefer to live alone [38]. In Iran the care of elderly people in nursing homes or institutions are largely deemed unacceptable by the general public. However, due to recent changes of family size, migration and accommodation problems, there is a trend to transfer elders to nursing homes for better care [7].

Last but not least, economic status recognized as the most important predictor of HRQoL of elderly among other factors examined. Having enough money is important to QoL, not only to cover and meet the basic needs of life, but it is a very influential factor to participate in society, to enjoy people themselves of hobbies, holidays and luxuries and to make elderly free of worry about emergencies in life and unexpected expenses in future [13]. This is one of the reasons that elderly Iranians have considerably lower HRQoL scores compared with the scores of elderly in developed world. Omnibus survey in the UK demonstrated considerably better scores both physically and mentally for British elderly [40].

Other determinants of QoL in older people, were identified as social networks, standards of living, activity, spirituality, material resources and physical and social environmental factors [9]. In addition, people's expectation of life, optimism or pessimism, having good health and physical functioning, participating in social activities and having social and family supports, good community services such as transport, safety and having control on their own life were found to be important elements of health-related quality of life in elderly people [41]. 
This study, however, has several limitations. The study design was cross-sectional and it is hence difficult to establish cause-effect relationships between QoL and sociodemographic characteristics. A longitudinal study is needed to investigate the relationships in the future. Our sampling took into account only non-institutionalized individuals and excluded those living in nursing homes, hospitals for the chronic diseases. As such the design might have biased our results in a way that we recruited a sample of better off elderly people. Another limitation of this study is that we collected the data via face-to face interviews by 12 interviewers rather than self-reporting method. Thus, although interviewers were trained, there are possibilities that they might be collected the data differently. In addition, some elderly might be either 'underreported' or 'over-reported' their QoL depending on the time and place of interviews. Social desirability bias, for instance, may cause some to over-report their QoL. This bias is likely to be stronger in a face-to-face interview compared to a self-report questionnaire [42]. Mood states of people at the time of answering QoL questions also can affect responses [37]. However such limitations should be minimized in the future studies. Further studies could also be completed to identify the likely causes of inequalities in health in terms of gender, living status and socioeconomic position. Additionally, qualitative studies such as in-depth interviews with elderly can be used to have a better understanding on the topic.

\section{Conclusion}

The study findings indicate that elderly people living in Tehran, Iran suffer from relatively poor HRQoL; particularly elderly women and those with lower education. Indeed to improve quality of life among elderly Iranians much more attention should be paid to all aspects of their life including their health, and economic status. It is hoped that this survey could add to the existing literature on HRQoL of old people in Iran and enable informed decisions to be made by policy makers.

\section{Abbreviations}

QoL: Quality of life; HRQoL: Health-related quality of life; SF-36: Short-Form 36 Health Survey; PCS: Physical Component Summary; MCS: Mental Component Summary; GH: General Health; MH: Mental Health; PF: Physical Functioning; BP: Bodily Pain; RE: Role Emotional; RP: Role Physical; SF: Social Functioning; VT: Vitality.

\section{Competing interests}

The authors declare that they have no competing interests.

\section{Authors' contributions}

MT was the principal investigator and wrote the paper. MA was also the principal author of this paper. He managed the study throughout the work. He contributed equally to this work with MT. AM has made substantial contributions to the analysis and interpretation of the data. He also reviewed the first draft and wrote the final version of the manuscript. All authors read and approved the final manuscript.

\section{Acknowledgements}

We are grateful for the participation of the elderly people in this study. This study was supported by Tehran University of Medical Sciences. We would like to appreciate sincerely assistance of some staff of Health Management and Economics Sciences Department and Professor Kazem Mohammad from Biostatistics Department of the University and also the help of Mr. Rohollah Asgari in conducting this research. We also appreciate excellent guidance of Professor Emily Grundy from LSHTM and also Dr. Helena Tunstall from York University of the UK who kindly supported the writing of this paper.

\section{References}

I. Weil DN: Population aging. [http://ssrn.com/abstract=893608].

2. Gavrilov LA, Heuveline P: Aging of Population. In The Encyclopedia of Population Edited by: Demeny P, McNicoll G. New York, Macmillan; 2003:32-37.

3. Jogataee M: The Elderly World Day. Monthly Magazine of University of Social Welfare and Rehabilitation Science, Tehran, Iran 2005, I I:2. [in Persian]

4. United Nations: World Population Ageing: 1950-2050, Countries of area: Iran (Islamic Republic of). [http://www.un.org/ esa/population/publications/worldageing 1 9502050/pdf/ / 3iran(.pdf].

5. Mehryar AH, Ahmad-Nia S: Age-Structural Transition in Iran: Short and Long-term Consequences of Drastic Fertility Swings During the Final Decades of Twentieth Century, presented at the CICRED Seminar on "Age-Structural Transitions: Population Waves, Disordered Cohort Flows and the Demographic Bonus", Paris, 23-26 February 2004.

6. Statistical Centre of Iran [http://amar.sci.org.ir/index e.aspx]

7. Teymoori F, Dadkhah A, Shirazikhah M: Social welfare and health (mental, social, physical) status of aged people in Iran. Middle East Journal of Age and Ageing 2006, 3:39-45.

8. Sheykhi MT: Elderly People Living in Nursing Homes in Iran. African and Asian Studies 2004, 3(2): 103-I I8.

9. Bond J, Corner L: Quality of Life and Older People. Maidenhead: Open University Press; 2004.

10. O'Connor R: Measuring quality of life in health. Ist edition. Churchill Livingstone; 2004.

II. Revicki DA: Health related quality of life in the evaluation of medical therapy for chronic illness. The J of Family Practice 1989, 29:377-387.

12. Imberly CK, Dana DM: Using the SF-36 to determine perceived health-related quality of life in rural Idaho Seniors. Journal of Allied Health 2006, 35: I56-I6I.

13. Bowling A: Aging well, quality of life in older age. First edition. Maidenhead: Open University Press; 2005.

14. Gallicchio L, Hoffman SC, Helzlsouer KJ: The relationship between gender, social support, and health-related quality of life in a community-based study in Washington County Maryland. Qual Life Res 2007, 16:777-786.

15. Farquhar M: Elderly people's definitions of quality of life. Social Sciences and Medicine 1995, 41: | 439-1446.

16. Statistical Centre of Iran: General Characteristics of Ostans according to their administrative divisions at the end of 1383 (2005 CE).

17. Hayes V, Morris J, Wolfe C, Moran M: The SF-36 health survey questionnaire: is it suitable for us with older adults? Age Ageing 1995, 24:120-125.

18. Montazeri A, Goshtasebi A, Vahdaninia M, Gandek B: The Short Form Health Survey (SF-36): translation and validation study of the Iranian version. Qual Life Res 2005, 14:875-882.

19. Lauridsen J, Christiansen T, Hakkinen U: Measuring inequality in self reported health: discussion of a recently suggested approach using Finnish data. Health Econ 2004, 13:725-732. 
20. Kaldi AR: A study on physical, social and mental problems of the elderly in District I 3 of Tehran. Middle East Journal of Age and Ageing 2004, 1:31-39.

2I. Kaldi AR: Employment status of the elderly referring to the social security organization of Tehran city. Middle East Journal of Age and Ageing 2005, 2:62-69.

22. Tajvar M, Farziyanpour F: Elderly health and a review on different aspects of their life. Tehran: Nasle Farda and Arjmand Press; 2004.

23. Vahdaninia M, Goshtasebi A, Montazeri A, Maftoon F: Healthrelated quality of life in an elderly population in Iran: a population-based study. Payesh 2005, 4: I |3-I20. [in Persian]

24. World Bank: Iran National Health Accounts. 200I [http:// www.who.int/nha/docs/en/Iran NHA report english.pdf].

25. Noro A, Aro S: Comparison of health and functional ability between non-institutional and least institutionalized elderly in Finland. The Gerontologist Washington 1997, 37:374-384.

26. Walters SJ, Munro JF, Brazier JE: Using the SF-36 with older adults: a cross-sectional community-based survey. Age Ageing 200I, 30:337-343.

27. Tsai SY, Chi LY, Lee LS, Chou P: Health-related quality of life among urban, rural and island community elderly in Taiwan. Journal of Formos Medicine Association 2004, 103:196-204.

28. Knurowski T, Lazic D, van Dijk JP, Geckova AM, Tobiasz-Adamczyk B: Survey of health status and quality of life of the elderly in Poland and Croatia. Medicine Journal 2004, 45:750-56.

29. Lee Y, Shinkai SA: A comparison of correlates of self-reported health and function disability of older person in the Far East: Japan and Korea. Archive of Gerontology and Geriatrics 2003, 37:63-76.

30. Annandale E, Hunt K, ed: Gender inequalities in health: research at the crossroads Buckingham: Open University Press; 1999.

31. Oyegbite KS: Perspective on gender and health [http:www.fordham.edu/images/academics/office of research/undp/ oyeg bite.ppt]

32. Hellstrom $\mathrm{Y}$, Hallberg IR: Determinants and characteristics of help provision for elderly people living at home and in relation to quality of life. Scandinavian Journal of Caring Sciences 2004, I 8:387-395.

33. Mowad L: Correlation of Quality of life in older adult veterans. Western Journal of Nursing Research 2004, 26:293-306.

34. Lasheras C, Patterson AM, Casado C, Fernandez S: Effects of education on the quality of life, diet, and cardiovascular risk factors in an elderly Spanish community population. Experimental Aging Research 200I, 27:257-270.

35. United Nations: Socioeconomic characteristics of the older population. World Population Ageing: 1950-2050 [http:// www.un.org/esa/population/publications/worldageing | 9502050].

36. Victor C, Scambler S, Bond J, Bowling A: Loneliness in later life. In Growing Older: Quality of Life in Older Age Edited by: Walker A, Hagen Hennessy C. Maidenhead: Open University Press; 2004.

37. Walker A: Understanding quality of life in old age Maidenhead: Open University Press; 2005

38. Bowling A, Grundy E, Farquhar M: Living Well into Old Age First edition. Glasgow: Open University Press; 1997.

39. Tunestall J: Old and Alone: A Sociological Study of Old People London: Routledge \& Kegan; 1996.

40. Bowling A, Bond M, Jenkinson C, Lamping DL: Short Form 36 (SF36) Health Survey questionnaire: which normative data should be used? Comparisons between the norms provided by the Omnibus Survey in Britain, the Health Survey for England and the Oxford Healthy Life Survey. Journal of Public Health Medicine 1999, 21:255-270.

4I. Bowling A, Gabriel Z, Banister D, Sutton S: Adding quality to quantity: older people's view on their quality of life and its enhancement. Sheffield: University of Sheffield; 2002.

42. DeMaio T]: Social desirability and survey measurement: a review. In Surveying Subjective Phenomena Volume 2. Edited by: Turner CF, Martin E. New York: Russell Sage Foundation; 1984

\section{Pre-publication history}

The pre-publication history for this paper can be accessed here: http://www.biomedcentral.com/1471-2458/8/323/pre pub
Publish with BioMed Central and every scientist can read your work free of charge

"BioMed Central will be the most significant development for disseminating the results of biomedical research in our lifetime. "

Sir Paul Nurse, Cancer Research UK

Your research papers will be:

- available free of charge to the entire biomedical community

- peer reviewed and published immediately upon acceptance

- cited in PubMed and archived on PubMed Central

- yours - you keep the copyright
BioMedcentral 